\title{
Barriers to Dental Care in Individuals with Special Healthcare Needs in Qatif, Saudi Arabia: A Caregiver's Perspective
}

This article was published in the following Dove Press journal: Patient Preference and Adherence

\author{
Amal Alfaraj' \\ Hassan S Halawany ${ }^{2}$ \\ Muntasar T Al-Hinai ${ }^{3}$ \\ Abid H Al-Badr ${ }^{2}$ \\ Marwa Alalshaikh ${ }^{4}$ \\ Khalifa S Al-Khalifa $\mathbb{1 D}^{5}$ \\ 'Prosthodontics Residency Program, \\ Department of Prosthodontics, School of \\ Dentistry, Indiana University, Indianapolis, \\ IN, USA; ${ }^{2}$ Department of Periodontics \\ and Community Dentistry, College of \\ Dentistry, King Saud University, Riyadh, \\ Saudi Arabia; ${ }^{3}$ Dental and Maxillofacial \\ Surgery Department, Sultan Qaboos \\ University Hospital, Sultan Qaboos \\ University, Muscat, Sultanate of Oman; \\ ${ }^{4}$ Periodontics Fellowship Program, \\ College of Dentistry, Imam Abdulrahman \\ Bin Faisal University, Dammam, Saudi \\ Arabia; ${ }^{5}$ Department of Preventive \\ Dental Sciences, College of Dentistry, \\ Imam Abdulrahman Bin Faisal University, \\ Dammam, Saudi Arabia
}

Objective: Access to dental care is a key factor influencing oral health outcomes. Individuals with special healthcare needs are at risk of not having access to dental care services which they need to maintain their oral health. This study assessed the magnitude of this problem and identified barriers responsible for the difficulties in accessing dental care in Qatif, Saudi Arabia, as reported by caregivers of individuals with special healthcare needs.

Methods: This cross-sectional study collected data using a self-administered survey questionnaire from caregivers of individuals with special healthcare needs across 11 centers (eight special needs centers and three schools) in Qatif, Eastern Province of Saudi Arabia, between February and April 2019.

Results: A total of 186 caregivers participated in the study, 102 (54.8\%) of whom reported difficulties in getting access to dental care. The key barriers included lack of time on the part of caregivers (60.8\%), unsuitable clinic environment (53.9\%), difficulties with transportation $(51.9 \%)$, medical/health status of the individual with special healthcare needs $(51.0 \%)$, and geographically distant dental clinics (51.0\%). Caregiver demographics (age, gender, and educational level) had no significant influence on the difficulties reported by caregivers in getting access to dental care for individuals with special healthcare needs ( $p>0.05)$.

Conclusion: A large proportion of caregivers in Qatif, Saudi Arabia, experience difficulties with access to dental care services for individuals with special healthcare needs. The most common barriers are physical accessibility of dental facilities (for individuals with special healthcare needs), affordability, and lack of skills and knowledge of dental care providers.

Keywords: health services accessibility, dental care for disabled, caregivers, Saudi Arabia

\section{Introduction}

Over the years, access to health care has received increasing attention as a key determinant of health outcomes. Access to dental care is an important but complex component of the debates surrounding access to health care in general. While a significant proportion of the global population still has issues with access to dental care, individuals with special healthcare needs are even more at risk of inadequate access to the dental care services they need to maintain their oral health and manage dental conditions. ${ }^{1-3}$ A number of studies have identified dental care as one of the most prevalent unmet healthcare needs among people with special needs. $^{2,4,5}$ Even though this is a problem among general populations, it is a bigger issue among those with special healthcare needs; especially those with greater limitations attributable to disability. ${ }^{6-10}$
Correspondence: Amal Alfaraj

Prosthodontics Residency Program, Department of Prosthodontics, School of Dentistry, Indiana University, Indianapolis, IN, USA

Email asalfara@iu.edu 
Globally, estimates indicate that as many as 500 million people experience one or more disability arising from physical, mental, or sensory impairments; and as a result, require special care. ${ }^{11}$ In Saudi Arabia alone, about one million people live with one or more disability; pointing at the need for special care considerations for this group of people. ${ }^{12}$ Considering the "peculiarity" of individuals with disabilities, they require "special considerations when receiving dental treatments" as the nature of their circumstances often presents challenges while accessing dental care. ${ }^{13}$ However, many of the individuals with special healthcare needs do not have the required access. ${ }^{14}$ Being one of the most marginalized groups in society, discrimination, lack of care, and inequity bars individuals with disabilities from receiving many of their rights, especially in education and health care. ${ }^{15-17}$

With increasing global awareness of the importance of oral health among members of the public and dental care professionals, it would be expected that there should be almost universal access to dental services in Saudi Arabia. However, this is not the case. A Saudi study showed that $46.2 \%$ of those with special healthcare needs have difficulties accessing dental care, and $84.7 \%$ were only attended to in the dental clinic for emergency treatment. ${ }^{3}$ A number of barriers have been associated with this poor access to dental care by individuals with special healthcare needs. These include poor income level, low levels of parent education, and not having health/dental insurance coverage. ${ }^{18-21}$ The influence of low socioeconomic status (SES) on access to dental care has been well documented, with families in lower socioeconomic categories more likely than those in higher categories to experience challenges with access to dental services. ${ }^{22}$ Additionally, there are psychological, behavioral, and physical complications associated with these special healthcare needs individuals who may already have complex medical backgrounds that prevent them from receiving the dental care they require. ${ }^{23-26}$ From the aspect of dental care professionals, the lack of special care training skills among dentists often makes them uncomfortable treating these patients because of their resistant and maladaptive behavior. ${ }^{19,27,28}$

In order to explore reasons why there is poor access to dental care services in Saudi Arabia, it is important to fully understand the barriers experienced by special healthcare needs individuals. Alumran et al and Al-Sheri attempted to document the magnitude of the problems and identify barriers to dental care for these individuals in Saudi
Arabia. $^{3,13}$ However, considering the uneven distribution of the population across the regions and cities in the country with varying socioeconomic and public health circumstances, it becomes necessary to further investigate this in other parts of Saudi Arabia. This study aimed to assess caregivers' responses regarding the magnitude of the problems and barriers to accessing dental care experienced by special healthcare needs individuals in Qatif, Saudi Arabia. The objectives were to determine the proportion of individuals with special healthcare needs that have experienced difficulties in accessing dental care and identify the main barriers responsible for this.

\section{Methods}

\section{Study Design and Population}

This cross-sectional study was conducted in the city of Qatif, Eastern Province of Saudi Arabia with a population over 98,000. Participants for the study were selected from special needs centers affiliated with the Saudi Ministry of Social Affairs, public schools with integrated special needs education, and charity organizations taking care of special healthcare needs individuals in Qatif. A total of 11 centers were involved in the study on the basis of their assent to the study being conducted at their locations. These centers provide supportive care and attend to the daily needs of special healthcare needs individuals across all ages.

The study focused on caregivers of individuals with special healthcare needs across these locations. Using a convenience sampling method, participants who met the study's main inclusion criteria of i) being a caregiver for a special healthcare needs individual, ii) with a history of taking the individual with special healthcare needs under their care to the dentist, and iii) willing to provide informed consent, were allowed to participate in the study and sequentially recruited until the total sample size had been met. Those who were not willing to provide informed consent or had not been taking care of a special healthcare needs individual were excluded. Only one caregiver was randomly selected for each healthcare needs individual (in cases where there was more than one caregiver available), indicating an equal number of caregivers and individuals with special healthcare needs. The authors were responsible for identifying those who met the study's criteria, provided them with brief information on the study's goals and procedures, and obtained informed consent. 


\section{Data Collection and Analysis}

A self-administered survey questionnaire in Arabic designed purposely for the study was distributed to participants in each center between February and April 2019. This questionnaire was adapted from previously used surveys in studies. ${ }^{3,28}$ The data collection tool was piloted on a sample of 10 caregivers to ensure proper presentation, easy comprehension and completion of the questionnaire by the target population. The survey gathered information from the caregiver about the individual with special healthcare needs whom the caregiver cares for with respect to: i) their demographic information, ii) disability (as diagnosed by previous health care providers), iii) degree of access to dental care, and iv) difficulties associated with access to dental care.

The resulting information was compiled in an Excel spreadsheet where it was cleaned and transferred to Statistical Package for Social Science (SPSS) software, version 20 (Chicago, IL, USA) for analysis. The results of descriptive analysis were summarized in frequency (proportion) tables, while those of inferential analyses (chi squared tests) carried out to determine the presence and magnitude of associations between variables were summarized in an odds ratio table. The major and minor reasons why caregivers had experienced difficulties in getting their special healthcare care individuals under their care to see and be attended to by a dentist were later combined as barriers to accessing dental care. Also, the odds ratio table shows barriers to accessing dental care and associations with age, gender, and level of education. The table presents this information as individuals who had experienced the challenge (major and minor reasons) versus those who had not (no reason) with regards to age, gender, and level of education. Significant differences were considered at a $p$-value of $<0.05$.

\section{Ethical Approval}

Ethical approval was obtained from the Institutional Review Board at the Imam Abdulrahman Bin Faisal University, Dammam. Informed consent was obtained from all eligible participants and the study was carried out in line with ethical principles outlined in the Helsinki Declaration.

\section{Results}

A total of 186 caregivers participated across the eleven study locations in Qatif. This was based on a response rate of $26.6 \%$ out of the 700 caregivers who were approached for the study. Of the participating caregivers, the majority of them were females $(64.5 \%$; Table 1$)$. A larger proportion $(30.6 \%)$ of the caregivers were between the ages of 35 and 44 years, closely followed by those in the 25-34 years category (28.0\%). With regards to education, $36.0 \%$ of the caregivers had high school education, $34.4 \%$ had college or higher education, while $29.6 \%$ had no education or did not get to high school level. Each caregiver provided information on one individual with special healthcare needs. The majority of individuals with special healthcare needs were of male gender (67.2\%) and had developmental disabilities (44.6\%). The remaining had sensory impairment (26.9\%), physical disabilities (18.3\%), and behavioral and emotional disorders $(10.2 \%)$.

As many as $102(54.8 \%)$ of the caregivers reported difficulties in accessing dental care for special healthcare needs individuals in the community (Table 2), while the rest responded negative. Also, $88.2 \%$ of them indicated that they were willing to support the presence of a specialized dental facility/hospital that can provide dental care for special healthcare needs individuals.

The study tested 17 potential reasons for the difficulties that caregivers experienced with accessing dental care for the special healthcare needs individuals in their care $(n=102)$. As summarized in Table 3, the most common

Table I Demographic Distribution of the Study Participants

\begin{tabular}{|l|l|l|l|l|}
\hline Group & Variables & Values (n=186) & $\mathbf{N}$ & $\%$ \\
\hline Caregivers & Gender & Male & 66 & 35.5 \\
& & Female & 120 & 64.5 \\
\cline { 2 - 5 } & \multirow{2}{*}{ Age } & Under 25 years & 39 & 21.0 \\
& & $25-34$ years & 52 & 28.0 \\
& & $35-44$ years & 57 & 30.6 \\
& & Over 45 years & 38 & 20.4 \\
\cline { 2 - 5 } & Level of & Under high school & 55 & 29.6 \\
& education & High school & 67 & 36.0 \\
& & College and higher & 64 & 34.4 \\
\hline \multirow{3}{*}{$\begin{array}{l}\text { Special } \\
\text { needs }\end{array}$} & Special & Behavioral \& emotional & 19 & 10.2 \\
& needs & Developmental disability & 83 & 44.6 \\
& types & Physically disabled/others & 34 & 18.3 \\
& & Sensory impairment & 50 & 26.9 \\
\cline { 2 - 5 } & Gender & Male & 125 & 67.2 \\
& & Female & 61 & 32.8 \\
\hline
\end{tabular}

Note: $\mathrm{N}$ and $\mathrm{n}$ represent the frequency and sample size respectively; \% - sample proportion. 
Table 2 Caregivers' Perceptions of Issues with Access to Dental Care in the Community

\begin{tabular}{|c|c|c|c|}
\hline Variables & $\begin{array}{l}\text { Values } \\
(n=186)\end{array}$ & $\mathbf{N}$ & $\%$ \\
\hline $\begin{array}{l}\text { Does the person you care for face any } \\
\text { difficulties in accessing dental care in } \\
\text { your community? }\end{array}$ & $\begin{array}{l}\text { Yes } \\
\text { No } \\
\text { Do not know }\end{array}$ & $\begin{array}{l}102 \\
65 \\
19\end{array}$ & $\begin{array}{l}54.8 \\
34.9 \\
10.2\end{array}$ \\
\hline $\begin{array}{l}\text { Do you support the presence of } \\
\text { a specialized dental hospital/center } \\
\text { that treats special needs individuals? }\end{array}$ & $\begin{array}{l}\text { Yes } \\
\text { No } \\
\text { Do not know }\end{array}$ & $\begin{array}{l}164 \\
12 \\
10\end{array}$ & $\begin{array}{l}88.2 \\
6.5 \\
5.4\end{array}$ \\
\hline
\end{tabular}

Note: $\mathrm{N}$ and $\mathrm{n}$ represent the frequency and sample size respectively; \% - sample proportion.

reasons for these difficulties were issues with lack of time on the part of caregivers $(60.8 \%)$, dental condition of the special healthcare needs individual not being too serious enough to see a dentist (55.8\%), and the design and environment of the dental clinic which were disturbing to special healthcare needs individuals (53.9\%). Others include difficulties with transportation to the dental clinic (51.9\%), medical health status of the special healthcare needs individual which hinders him/her from receiving immediate dental care $(51.0 \%)$, and large geographical distances between the dental clinic and the special healthcare needs individual (51.0\%).

Among all the reasons tested, there were a number of them that the caregivers considered major reasons for the challenges they had been experiencing with access to dental care. These included issues with lack of time on the part of caregivers $(41.2 \%)$, the environment and design of the dental clinic being too disturbing for individuals with special healthcare needs $(36.3 \%)$, special healthcare need individual requiring informed consent from primary physician for hospitalization (33.3\%), and special healthcare need individual's dental condition not being serious enough to see a dentist (33.3\%).

Going further to assess the influence of caregiver age, gender, and level of education on the prevalence of these difficulties, Table 4 shows that caregiver demographics places some caregivers at higher risk of experiencing these difficulties that make access to dental care challenging than others. Even though not found to be statistically significant, caregivers aged less than 35 years were more likely than older caregivers to have special healthcare needs individuals under their care experiencing the following difficulties with access to dental care: i) dental clinic waiting area and general services not being suitable (odds ratio, OR 1.2, 95\% CI: 0.5-2.7), ii) dental clinic not equipped to facilitate treatment of special healthcare needs individuals (OR 1.7, 95\% CI: 0.7-4.3), iii) dental staff not friendly or do not know how to manage special healthcare needs individuals (OR 1.7, 95\% CI: 0.7-3.9), iv) medical health status of the special healthcare needs individual hindering him/her from receiving immediate dental care (OR 1.5, 95\% CI: 0.6-3.5), and v) special healthcare needs individual unable to sit on the dental chair or cooperate with the dentist (OR 1.3, 95\% CI: $0.6-2.8)$.

Similarly, male caregivers were more likely than female caregivers to have issues with disturbing dental

Table 3 Reasons Given by Caregivers for Difficulties in Accessing Dental Care for Special Care Needs Individuals in the Community

\begin{tabular}{|c|c|c|c|c|}
\hline Variables $(n=102)$ & Major Reason & Minor Reason & Not a Reason & Do Not Know \\
\hline Dentist unwilling to treat or inadequately trained in treating patients with special needs & II (10.8\%) & $9(8.8 \%)$ & $64(62.7 \%)$ & $18(17.6 \%)$ \\
\hline Dental clinic environment, colors, light and design are disturbing to special needs persons & $37(36.3 \%)$ & $18(17.6 \%)$ & $33(32.4 \%)$ & $14(13.7 \%)$ \\
\hline Dental clinic waiting area and general services (example: toilets) are not suitable & 31 (30.4\%) & $14(13.7 \%)$ & $45(44.1 \%)$ & $12(11.8 \%)$ \\
\hline Dental clinic is not equipped to facilitate treatment of special needs individuals & $12(11.8 \%)$ & $13(12.7 \%)$ & $60(58.8 \%)$ & $17(16.7 \%)$ \\
\hline Dental staff are not friendly or do not know how to manage special needs individuals & $23(22.5 \%)$ & $22(21.6 \%)$ & $45(44.1 \%)$ & $12(11.8 \%)$ \\
\hline Patient has communication difficulties with the dentist during treatment visits & $12(11.8 \%)$ & $17(16.7 \%)$ & $65(63.7 \%)$ & $8(7.8 \%)$ \\
\hline Medical health status of the patient hinders him/her from receiving immediate dental care & $32(31.4 \%)$ & $20(19.6 \%)$ & $38(37.3 \%)$ & $12(11.8 \%)$ \\
\hline Patient needs informed consent from his physician or needs hospitalization & $34(33.3 \%)$ & $8(7.8 \%)$ & $46(45.1 \%)$ & $14(13.7 \%)$ \\
\hline Patient is afraid of the dentist & $25(24.5 \%)$ & $13(12.7 \%)$ & $57(55.9 \%)$ & $7(6.9 \%)$ \\
\hline Patient unable to sit on the dental chair or cooperate with the dentist & $30(29.4 \%)$ & $19(18.6 \%)$ & $51(50.0 \%)$ & $2(2.0 \%)$ \\
\hline Patient's dental condition was not serious enough to see a dentist & $34(33.3 \%)$ & $23(22.5 \%)$ & $35(34.3 \%)$ & $10(9.8 \%)$ \\
\hline Dental centers/units that treat special needs patients are rare and limited & $7(6.9 \%)$ & $8(7.8 \%)$ & $81(79.4 \%)$ & $6(5.9 \%)$ \\
\hline Difficulty in getting appointments & II (10.8\%) & $10(9.8 \%)$ & $76(74.5 \%)$ & $5(4.9 \%)$ \\
\hline No time to visit the dentist & $42(41.2 \%)$ & $20(19.6 \%)$ & $33(32.4 \%)$ & $7(6.9 \%)$ \\
\hline Cost or financial difficulty & $24(23.5 \%)$ & $19(18.6 \%)$ & $55(53.9 \%)$ & $4(3.9 \%)$ \\
\hline Transportation difficulty & $29(28.4 \%)$ & $24(23.5 \%)$ & $44(43.1 \%)$ & $5(4.9 \%)$ \\
\hline Dental clinic is too far away & 31 (30.4\%) & $21(20.6 \%)$ & $48(47.1 \%)$ & $2(2.0 \%)$ \\
\hline
\end{tabular}


Table 4 Reasons for Difficulties with Access to Dental Care Expressed by Caregivers $(n=102)$

\begin{tabular}{|c|c|c|c|c|c|c|}
\hline \multirow[t]{2}{*}{ Reasons for Difficulties with Access to Dental Care $(n=102)$} & \multicolumn{2}{|l|}{ Age } & \multicolumn{2}{|c|}{ Gender } & \multicolumn{2}{|c|}{ Level of Education } \\
\hline & OR & $95 \% \mathrm{Cl}$ & OR & $95 \% \mathrm{Cl}$ & OR & $95 \% \mathrm{Cl}$ \\
\hline Dentist unwilling to treat or inadequately trained in treating patients with special needs & 0.82 & $0.30-2.24$ & 0.82 & $0.28-2.43$ & 1.49 & $0.51-4.35$ \\
\hline Dental clinic environment, colors, light and design are disturbing to special needs persons & 0.60 & $0.25-1.43$ & 1.31 & $0.52-3.31$ & 1.03 & $0.40-2.63$ \\
\hline Dental clinic waiting area and general services (example: toilets) are not suitable & 1.20 & $0.52-2.74$ & 1.48 & $0.62-3.52$ & 1.12 & $0.44-2.81$ \\
\hline Dental clinic is not equipped to facilitate treatment of special needs individuals & 1.66 & $0.65-4.26$ & 0.87 & $0.32-2.36$ & 1.41 & $0.51-3.93$ \\
\hline Dental staff are not friendly or do not know how to manage special needs individuals & 1.71 & $0.74-3.94$ & 1.00 & $0.42-2.40$ & 0.57 & $0.22-1.46$ \\
\hline Patient has communication difficulties with the dentist during treatment visits & 1.18 & $0.49-2.82$ & 1.48 & $0.60-3.65$ & 1.38 & $0.52-3.63$ \\
\hline Medical health status of the patient hinders him/her from receiving immediate dental care & 1.49 & $0.64-3.45$ & 0.91 & $0.38-2.17$ & 0.80 & $0.32-2.00$ \\
\hline Patient needs informed consent from his physician or needs hospitalization & 1.09 & $0.47-2.52$ & 0.75 & $0.30-1.85$ & 1.02 & $0.40-2.57$ \\
\hline Patient is afraid of the dentist & 0.57 & $0.25-1.30$ & 1.41 & $0.60-3.33$ & 1.42 & $0.57-3.53$ \\
\hline Patient unable to sit on the dental chair or cooperate with the dentist & 1.27 & $0.58-2.79$ & 1.27 & $0.55-2.91$ & 1.29 & $0.54-3.09$ \\
\hline Patient's dental condition was not serious enough to see a dentist & 0.76 & $0.33-1.76$ & 1.25 & $0.50-3.13$ & 0.71 & $0.28-1.81$ \\
\hline Dental centers/units that treat special needs patients are rare and limited & 0.44 & $0.14-1.41$ & 1.00 & $0.31-3.22$ & 0.63 & $0.16-2.44$ \\
\hline Difficulty in getting appointments & 0.55 & $0.21-1.49$ & 1.18 & $0.44-3.22$ & 0.77 & $0.25-2.35$ \\
\hline No time to visit the dentist & 1.13 & $0.49-2.64$ & 1.97 & $0.77-5.08$ & 0.76 & $0.30-1.88$ \\
\hline Cost or financial difficulty & 0.84 & $0.38-1.86$ & 0.89 & $0.38-2.11$ & 0.68 & $0.27-1.68$ \\
\hline Transportation difficulty & 0.87 & $0.39-1.94$ & 1.85 & $0.77-4.45$ & 0.80 & $0.33-1.91$ \\
\hline Dental clinic is too far away & 0.62 & $0.28-1.36$ & 0.74 & $0.32-1.70$ & 0.55 & $0.23-1.31$ \\
\hline
\end{tabular}

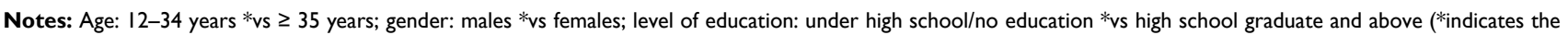
reference values). Level of significance set at $p<0.05$; none of the ORs were statistically significant.

Abbreviations: $\mathrm{OR}$, odds ratio; $95 \% \mathrm{Cl}, 95 \%$ confidence interval.

clinic environment and design (OR 1.3, 95\% CI: 0.5-3.3), unsuitable dental clinic waiting area and general services (OR 1.5, 95\% CI: 0.6-3.5), special healthcare needs individual having communication difficulties with the dentist during treatment visits (OR 1.5, 95\% CI: 0.6-3.7), special healthcare needs individual being afraid of the dentist (OR 1.4, 95\% CI: 0.6-3.3), special healthcare needs individual being unable to sit on the dental chair or cooperate with the dentist (OR 1.3, 95\% CI: 0.6-2.9), special healthcare needs individual's dental condition not being serious enough to see a dentist (OR 1.3, 95\% CI: 0.5-3.1), difficulty in getting dental appointments (OR 1.2, 95\% CI: 0.4-3.2), not having enough time to visit the dentist (OR 2.0, 95\% CI: $0.8-5.1$ ), and difficulties with transportation for dental appointments (OR 1.9, 95\% CI: 0.8-4.5).

With regards to the level of education, caregivers who had no education or had education below the level of high school were more likely than their counterparts with education at the level of high school and above to experience issues with: i) dentists unwilling to treat or inadequately trained in treating individuals with special healthcare needs (OR 1.5, 95\% CI: 0.51-4.35), ii) disturbing dental clinic environment and design (OR 1.0, 95\% CI: 0.40-2.63), iii) unsuitable dental clinic waiting area and general services (OR 1.1, 95\% CI: 0.44-2.81), iv) dental clinic unequipped to facilitate treatment of special healthcare needs individuals (OR 1.4, 95\% CI: 0.51-3.93), v) special healthcare needs individual having communication difficulties with the dentist during treatment visits (OR 1.4, 95\% CI: 0.52-3.63), vi) special healthcare needs individual being afraid of the dentist (OR 1.4, 95\% CI: $0.57-3.53$ ), and vii) special healthcare needs individual being unable to sit on the dental chair or cooperate with the dentist (OR 1.3, 95\% CI: 0.54-3.09). While it is key to note that none of these associations were found to be statistically significant, they are still valid reasons why caregivers experience difficulties with access to dental care for individuals with special healthcare needs.

\section{Discussion}

This paper describes the challenges and barriers that caregivers in Qatif, Saudi Arabia, experience with access to dental care services for individuals with special healthcare needs in their care. The responses suggest that caregivers are aware of the need for dental care for individuals with special healthcare needs under their care and that they try to get access to these services. In spite of this, a significant proportion of the special healthcare needs individuals still have challenges accessing the dental care they need. As much as $54.8 \%$ of the caregivers surveyed indicated that the individuals with special healthcare needs under their care experience difficulties with accessing dental care. This proportion is similar to the $46.2 \%$ reported by AlShehri as being the proportion of those who had experienced difficulties getting dental care for individuals with 
special healthcare needs, and as much as $55 \%$ of them had unmet dental needs. ${ }^{3}$ Similar findings have also been reported by investigators in other countries with approximately $35 \%$ of respondents indicating that they have difficulties in finding dentists willing to treat individuals who had disabilities. ${ }^{23,29}$ The implications of difficult access to dental services are poor dental outcomes such as higher prevalence of dental caries and need for restorative care. $^{30,31}$

As identified by the caregivers in this study, the most prevalent reasons for not being able to access dental care were lack of time on their part, poor design and environment of the dental clinic, transportation difficulties, medical health status of the special healthcare needs individual which hinders him/her from receiving immediate dental care, and having the dental clinic too far away from the intending special healthcare needs individual. Poor design and environment include lack of wheelchair accessible entrances and the presence of physical impediments that make it difficult for a disabled individual to get access to the facility. Other barriers included unfriendly and incompetent dental staff, cost/financial difficulty, fear of the dentist, communication issues between the special healthcare needs individual and the dentist, difficulty in getting dental appointments, and insufficient dental care centers to cater for special healthcare needs individuals. These barriers are congruent with those reported by other studies, ${ }^{3,13,32}$ and can be grouped into those relating to special healthcare needs individuals' ability to physically access dental facilities, inability to afford dental services due to high costs of treatment and insufficient financing for dental treatment, and the preparedness and willingness of dentists and dental nurses to treat special healthcare needs individuals. ${ }^{13}$

Furthermore, caregiver demographics appeared to have placed some individuals with special healthcare needs at a higher risk of experiencing access difficulties than others. For instance, caregivers aged less than 35 years were more likely than older caregivers to experience issues with unsuitable and unequipped dental clinics or not having time to take individual with special healthcare needs under their care to visit the dentist, among other challenges. Similarly, male caregivers were more likely to have issues with access to dental services due to unsuitable dental clinic environments and having fearful special healthcare needs individuals who were unable to sit on the dental chair or cooperate with the dentist. Not having enough education at least up to high school level meant that some caregivers were more likely to have challenges with access than others.

While some had it better than others, caregivers in this study who were male, younger than 35 years, and not enough education were more likely than others to have even more difficulties with access to dental services for the special healthcare needs individuals they were taking care of. As several researchers such as Gondlach et al, Gerreth and Borysewicz-Lewicka, and Chadwick et al have shown, multiple factors such as poor socioeconomic status of the families within which special healthcare needs individuals are brought up, young age, and low literacy worsens the ability of individuals with special healthcare needs to access care. ${ }^{1,6,7}$ Even though this study did not examine the influence of insurance on access to dental care, some of the caregivers in this study indicated that they had experienced cost and financial difficulties which could have been reduced if they had the benefit of insurance, as Al-Shehri emphasizes. ${ }^{3}$ Furthermore, individuals with disabling conditions are in many cases overwhelmed by the psychological, financial, and physical demands of the disability in such a way that seeking dental care drops on their list of priorities. ${ }^{33,34}$ This is illustrated by the large proportion of caregivers in this study who had indicated that the special healthcare needs individual's condition was either not serious enough to see the dentist based on their self-assessment or they did not have enough time to take the special healthcare needs individual to see the dentist.

Another factor that needs to be considered is the lack of preparedness, on the part of dental care providers, to take care of individuals with special healthcare needs. Even though dental staff were not directly asked as part of the study, many of the caregivers indicated that some dental staff in the dental facilities they visited did not know how to cater for individuals with special healthcare needs, neither did they have adequate infrastructure to cater for this special clientele. Studies have extensively documented how much of a problem this is in the developed world. This has been attributed in part to i) inadequate training of dental professionals on how to take care of individuals with special healthcare needs and ii) lack of necessary equipment and infrastructure for individuals with disabilities. ${ }^{3,13,35-37}$

In generalizing this study's findings, care needs to be taken in considering the limitations encountered during the course of the study. Firstly, the response rate of $26.6 \%$ is below the normal range for surveys. ${ }^{38}$ This may be 
explained by the lack of incentive to participate in the study, unawareness of this type of surveys, and/or lack of time. Considering that this study used a self-administered questionnaire which is based on caregivers' perceptions rather than on objective data, there is an increased chance of bias as participants might provide a range of skewed responses based on personal desirability. Also, the conduct of the study among caregivers of special healthcare needs individuals housed in special care facilities rather than at home suggests caution in generalizing the study to all individuals with disabilities. Further studies will be required to test the barriers identified in this study and find out the extent to which they made access to dental care difficult. Also, it will be important to obtain the perspective of dental care practitioners with regards to access to dental care for individuals with special healthcare needs.

\section{Conclusion}

It is clear that caregivers of individuals with special healthcare needs in Qatif, Saudi Arabia, experience some difficulties with access to dental care services for individuals with special healthcare needs. This is mostly due to special healthcare needs individuals' inability to physically access dental facilities, inability to afford dental services due to high costs of treatment, and the unpreparedness and unwillingness of dental care practitioners to treat individuals with special healthcare needs. Considering the importance of dental care to the overall health of individuals with special healthcare needs, there is a need for the inclusion of dental care as a standard component of comprehensive care for these individuals. Also, there needs to be deliberate actions to address other barriers such as improved training for dental care practitioners, and investments in equipment and other physical infrastructure to support the dental care of individuals with disabilities.

\section{Disclosure}

The authors report no conflicts of interest for this work.

\section{References}

1. Gondlach C, Catteau C, Hennequin M, Faulks D. Evaluation of a care coordination initiative in improving access to dental care for persons with disability. Int J Environ Res Public Health. 2019;16(15):2753. doi:10.3390/ijerph16152753

2. Brickhouse TH, Farrington FH, Best AM, Ellsworth CW. Barriers to dental care for children in Virginia with autism spectrum disorders. $J$ Dent Child. 2009;76(3):188-193.
3. Al-Shehri SAM. Access to dental care for persons with disabilities in Saudi Arabia (caregivers' perspective). J Disabil Oral Health. 2012;13(2):51-61. doi:10.4483/JDOH 006AL-shehri11

4. Newacheck PW, Hughes DC, Hung $-\bar{Y}-Y$, Wong S, Stoddard JJ. The unmet health needs of America's children. Pediatrics. 2000;105(4 Pt 2):989-997.

5. Mouradian WE, Wehr E, Crall JJ. Disparities in children's oral health and access to dental care. JAMA. 2000;284(20):2625-2631. doi:10.1001/jama.284.20.2625

6. Chadwick D, Chapman M, Davies G. Factors affecting access to daily oral and dental care among adults with intellectual disabilities. $J$ Appl Res Intellect Disabil. 2018;31(3):379-394. doi:10.1111/jar.12415

7. Gerreth K, Borysewicz-Lewicka M. Access barriers to dental health care in children with disability. A questionnaire study of parents. $J$ Appl Res Intellect Disabil. 2016;29(2):139-145. doi:10.1111/jar.12164

8. Lewis C, Robertson AS, Phelps S. Unmet dental care needs among children with special health care needs: implications for the medical home. Pediatrics. 2005;116(3):426-431. doi:10.1542/peds.2005-0390

9. Lewis $\mathrm{CW}$. Dental care and children with special health care needs: a population- based perspective. Acad Pediatr. 2009;9(6):420-426. doi:10.1016/j.acap.2009.09.005

10. Kancherla V, Braun KVN, Yeargin-Allsopp M. Dental care among young adults with intellectual disability. Res Dev Disabil. 2013;34 (5):1630-1641. doi:10.1016/j.ridd.2013.02.006

11. Holder M, Waldman HB, Hood H. Preparing health professionals to provide care to individuals with disabilities. Int J Oral Sci. 2009;1 (2):66-71. doi:10.4248/ijos.09022

12. Waldman HB, Al-Nowaiser AM, Hamed MT, Perlman SP. Dentistry for individuals with special needs in Saudi Arabia: a commentary. J Disabil Oral Health. 2010;11(2):57.

13. Alumran A, Almulhim L, Almolhim B, Bakodah S, Aldossary H, Alakrawi Z. Preparedness and willingness of dental care providers to treat patients with special needs. Clin Cosmet Investig Dent. 2018;10:231-236. doi:10.2147/CCIDE.S178114

14. Barry S, O'Sullivan EA, Toumba KJ. Barriers to dental care for children with autism spectrum disorder. Eur Arch Paediatr Dent. 2014;15(2):127-134. doi:10.1007/s40368-013-0075-y

15. Hatton C, Emerson E. Introduction: health disparities, health inequity, and people with intellectual disabilities. Academic Press.Int Rev Res Dev Disabil. 2015;48:1-9. doi:10.1016/bs.irrdd.2015.04.001

16. Ali A, Scior K, Ratti V, Strydom A, King M, Hassiotis A. Discrimination and other barriers to accessing health care: perspectives of patients with mild and moderate intellectual disability and their carers. PLoS One. 2013;8(8):1-13. doi:10.1371/journal. pone. 0070855

17. Llewellyn G, Vaughan C, Emerson E. Discrimination and the health of people with intellectual disabilities. Academic Press. Int Rev Res Dev Disabil. 2015;48:43-72I. doi:10.1016/bs. irrdd.2015.03.005

18. Habashneh RA, Al-Jundi S, Khader Y, Nofel N. Oral health status and reasons for not attending dental care among 12- to 16-year-old children with down syndrome in special needs centres in Jordan. Int $J$ Dent Hyg. 2012;10(4):259-264. doi:10.1111/j.16015037.2012.00545.x

19. Oredugba FA. Use of oral health care services and oral findings in children with special needs in Lagos, Nigeria. Spec Care Dent. 2006;26(2):59-65. doi:10.1111/j.1754-4505.2006.tb01511.x

20. Kenney MK, Kogan MD, Crall JJ. Parental perceptions of dental/oral health among children With and without special health care needs. Ambul Pediatr. 2008;8(5):312-320. doi:10.1016/j.ambp.2008.04.005

21. Schultz ST, Shenkin JD, Horowitz AM. Parental perceptions of unmet dental need and cost barriers to care for developmentally disabled children. Pediatr Dent. 2001;23(4):321-325.

22. Davis M. Issues in access to oral health care for special care patients. Dent Clin North Am. 2009;53(2):169-181. doi:10.1016/j. cden.2008.12.003 
23. Al Agili D, Roseman J, Pass M, Thornton J, Chavers L. Access to dental care in Alabama for children with special needs. J Am Dent Assoc. 2004;135(4):490-495. doi:10.14219/jada.archive.2004.0216

24. Murshid EZ. Oral health status, dental needs habits and behavioral attitude towards dental treatment of a group of autistic children in Riyadh, Saudi Arabia. Saudi Dent J. 2005;17(3):132-139.

25. Adenubi JO, Martinez JN. Dental health care at the disabled children's rehabilitation center in Riyadh. Saudi Dent J. 1997;9(1):9-13.

26. Al-Hussyeen A, Al-Sadhan SA. Oral hygiene practices and dietary habits among children with Down's syndrome in Riyadh, Saudi Arabia. Saudi Dent J. 2006;18(3):141-148.

27. Kagihara LE, Huebner CE, Mouradian WE, Milgrom P, Anderson BA. Parents' perspectives on a dental home for children with special health care needs. Spec Care Dent. 2011;31(5):170-177. doi:10.1111/j.1754-4505.2011.00204.x

28. Seid M, Sobo EJ, Gelhard LR, Varni JW. Parents' reports of barriers to care for children with special health care needs: development and validation of the barriers to care questionnaire. Ambul Pediatr. 2004;4(4):323-331. doi:10.1367/A03-198R.1

29. Hennequin M, Moysan V, Jourdan D, Dorin M, Nicolas E. Inequalities in oral health for children with disabilities: a French national survey in special schools. PLoS One. 2008;3(6):1-11. doi:10.1371/journal.pone.0002564

30. Shah A, Bindayel N, AlOlaywi F, Sheehan S, AlQahtani H, AlShalwi A. Oral health status of a group at a special needs centre in AlKharj, Saudi Arabia. J Disabil Oral Health. 2015;16(3):79-85. doi:10.4483/JDOH_Shah07

31. Isola G, Ramaglia L, Cordasco G, Lucchese A, Fiorillo L, Matarese G. The effect of a functional appliance in the management of temporomandibular joint disorders in patients with juvenile idiopathic arthritis. Minerva Stomatol. 2017;66(1):1. doi:10.23736/ S0926-4970.16.03995-3
32. Gordon SM, Dionne RA, Snyder J. Dental fear and anxiety as a barrier to accessing oral health care among patients with special health care needs. Spec Care Dent. 1998;18(2):88-92. doi:10.1111/ j.1754-4505.1998.tb00910.x

33. Stiefel DJ. Dental care considerations for disabled adults. Spec Care Dentist. 2002;22(3 Suppl):26S-39S.

34. Krishnan L, Iyer K, Kumar PDM. Barriers to utilisation of dental care services among children with special needs: a systematic review. Indian J Dent Res. 2020;31(3):486. doi:10.4103/ijdr.IJDR_542_18

35. Fenton SJ, Hood H, Holder M, May PB, Mouradian WE. The American Academy of Developmental Medicine and Dentistry: eliminating health disparities for individuals with mental retardation and other developmental disabilities. $J$ Dent Educ. 2003;67 (12):1337-1344. doi:10.1002/j.0022-0337.2003.67.12.tb03727.x

36. Clemetson JC, Jones DL, Lacy ES, Hale D, Bolin KA. Preparing dental students to treat patients with special needs: changes in predoctoral education after the revised accreditation standard. J Dent Educ. 2012;76(11):1457-1465. doi:10.1002/j.0022-0337.2012.76.11. tb05407.x

37. Holzinger A, Lettner S, Franz A. Attitudes of dental students towards patients with special healthcare needs: can they be improved? Eur J Dent Educ. 2020;24(2):243-251. doi:10.1111/eje.12490

38. Koneru A, Sigal MJ. Access to dental care for persons with developmental disabilities in Ontario. J Can Dent Assoc (Tor). 2009;75(2).
Patient Preference and Adherence

\section{Publish your work in this journal}

Patient Preference and Adherence is an international, peer-reviewed, open access journal that focusing on the growing importance of patient preference and adherence throughout the therapeutic continuum. Patient satisfaction, acceptability, quality of life, compliance, persistence and their role in developing new therapeutic modalities and compounds to optimize clinical outcomes for existing disease states are major areas of interest for the journal. This journal has been accepted for indexing on PubMed Central. The manuscript management system is completely online and includes a very quick and fair peer-review system, which is all easy to use. Visit http:// www.dovepress.com/testimonials.php to read real quotes from published authors. 